\title{
AVALIAÇÃO DE PREPARAÇÕES ANTIGÊNICAS DE STRONGYLOIDES STERCORALIS PARA O IMUNODIAGNÓSTICO DA ESTRONGILOIDÍASE
}

\author{
Cláudio Lúcio Rossi, Emília Emiko Hieda Takahashi, Angela Lauand \\ Sampaio Teixeira, Sílvia de Barros-Mazon e Rose Clélia Grion Trevisan
}

\begin{abstract}
Preparaçôes antigênicas de Strongyloides stercoralis para o imunodiagnóstico da estrongiloidiase têm sido tradicionalmente obtidas pela extração de antíg enos do parasita com solução salina. No presente trabalho, após obtenção da preparação antigênicade $\mathrm{S}$. stercoralis com extração salina, a fração residual foi solubilizada com uréia, $e$ as duas preparações foram avaliadas para o imunodiagnóstico da estrongiloidiase, através de uma técnica imunoenzimática. Não foram encontradas diferenças significativas entre as duas preparações, em termos de atividade antigência especifica e reatividade cruzada. A dificuldade de obtenção de larvas de S. stercoralis tem sido um fator limitante para o desenvolvimento de reações mais sensiveis $e$ específicas que possam ser empregadas no imunodiagnóstico da estrongiloidíase. A possibilidade de um maior rendimento, em termos de material antigênico ativo, abre perspectivas de fracionamento do extrato bruto do parasita, na tentativa de se encontrar fraçóes com maior atividade antigênica especifica e menor reatividade cruzada.
\end{abstract}

Palavras-chaves: Strongyloides stercoralis. Estrongiloidiase. Imunodiagnóstico. Antígenos.

Strongyloides stercoralis é um parasita com distribuição geográfica mundial, tendo maior prevalência em países tropicais ${ }^{5}$. A maioria dos indivíduos com estrongiloidíase é assintomática ou apresenta manifestações clínicas brandas, não patognomônicas $^{29}$.

O diagnóstico de estrongiloidíase tem sido tradicionalmente feito por métodos parasitológicos baseados na identificação de larvas de $S$. stercoralis nas fezes dos indivíduos infectados. Entretanto, muitos autores têm ressal tado a fal ta de sensibilidade desses métodos ${ }^{8} 10$.

O desenvolvimento de testes sorológicos confiáveis para o diagnóstico da estrongiloidíase pode ter grande utilidade em situações epidemiológicas e clínicas. Até o presente momento, poucas tentativas têm sido feitas para $o$

\footnotetext{
Trabalho realizado no Departamento de Patologia Clínica da Faculdade de Ciências Médicas da Universidade Estadual de Campinas, Campinas, SP.

Endereço para correspondência: Dr. Cláudio Lúcio Rossi. Depto. de Patologia Clínica/FCM/UNICAMP. CP: 6111, 13081-970 Campinas, SP.

Recebido para publicação em 30/12/92.
}

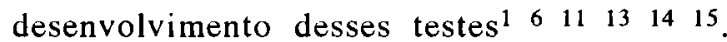
Tradicionalmente, preparações antigênicas de $S$. stercoralis, resultantes de extração de antígenos com solução salina, têm sido utilizadas nas técnicas sorológicas padronizadas. Todavia, tais preparações carecem de adequada sensibilidade e especificidade, por representarem extratos brutos do parasita. Uma das principais limitações encontradas no desenvolvimento de testes sorológicos mais sensíveis e específicos, é a dificuldade em se obter quantidades suficientes de antígenos que permitam seu posterior fracionamento e análise.

Estudos prévios têm mostrado que, após a extração de antígenos de Schistosoma mansoni com solução salina, a fração residual do parasita solubilizada com uréia, pode apresentar quantidades significativas de materiais antigênicos ativos ${ }^{16} 17$.

No presente trabalho, após obtenção de uma preparação antigênica de $S$. stercoralis com extração salina, uma segunda preparação antigênica foi obtida pela solubilização da fração residual com uréia, e as duas preparaçôes foram avaliadas para o imunodiagnóstico da estrongiloidíase, através de uma técnica imunoenzimática (ELISA). 
Rossi CL, Takahashi EEH, Teixeira ALS, Barros-Mazon S, Trevisan RCG. Avaliação de preparações antigênicas de Strongyloides stercoralis para o imunodiagnóstico da estrongiloidíase. Revista da Sociedade Brasileira de Medicina Tropical 26:83-87, abr-jun, 1993.

\section{MATERIAL E MÉTODOS}

\section{Reagentes}

Quando não especificado no texto, os reagentes foram obtidos da Sigma Chemical Co., Saint Louis, MO. Tris (hidroximetil) - amino metano (Tris) e peróxidode hidrogênio a $30 \%\left(\mathrm{H}_{2} \mathrm{O}_{2}\right)$ foram obtidos da Aldrich Co., Milwaukee, WI.

\section{Preparação dôs antígenos de $S$. stercoralis}

Larvas de $S$. stercoralis recuperadas de cultura de fezes com carvão, através de uma modificação do método de Baermann ${ }^{12}$, foram lavadas várias vezes por centrifugação e estocadas a $-70^{\circ} \mathrm{C}$ até o momento de uso. A preparação antigênica resultante da extração salina foi obtida segundo Gam, Neva e Krotoski ${ }^{3}$. Resumidamente, as larvas foram descongeladas e ressuspendidas em solução salina tamponada com fosfato $0,15 \mathrm{M}, \mathrm{pH} 7,2$ (SST), contendo $5 \mathrm{mM}$ de fluoreto de fenilmetilsulfonila (FFMS). Após fragmentação das larvas por sonicação $(2,5 \mathrm{~min})$, o material foi deixado sob agitaç...o lenta, a $4^{\circ} \mathrm{C}$, durante $18 \mathrm{~h}$, para a extração de antígenos. Após centrifugação a $32.000 \mathrm{xg}$, durante $30 \mathrm{~min}$, a $4^{\circ} \mathrm{C}$, o sobrenadante (preparação ES) foi cuidadosamente removido, aliquotado e estocado a $-70^{\circ} \mathrm{C}$. O precipitado, resultante da centrifugaçâo, foi ressuspendido em tampão Tris$\mathrm{HCl} 0,05 \mathrm{M}$, contendo uréia $8 \mathrm{M}$ e FFMS $5 \mathrm{mM}$, pH 8. O material foi sonicado como previamente descrito e deixado sob agitação lenta, a $4^{\circ} \mathrm{C}$, durante $2 \mathrm{~h}$. Após centrifugação a $32.000 \mathrm{xg}$, por $30 \mathrm{~min}, \mathrm{a}^{\circ} \mathrm{C}$, o sobrenadante foi cuidadosamente removido 2 submetido a cromatografias de exclusão em colunas PD-10 (Pharmacia Fine Chemicals, Piscataway, $\mathrm{NJ}$ ), equilibradas com tampão Tris- $\mathrm{HCl} 0,05 \mathrm{M}, \mathrm{pH}$ 8 , contendo $0,2 \mathrm{M}$ de $\mathrm{NaCl}$. O eluente contendo proteínas (preparação EU) foi aliquotado e estocado a $-70^{\circ} \mathrm{C}$.

\section{ELISA}

A técnica imunoenzimática atilizada neste trabalho foi adaptada a partir de uma técnica previamente descrita para a detecção de anticorpos específicos da classe IgG anti-S. stercoralis ${ }^{11}$. As concentrações protéicas das preparações antigênicas, bem como a concentração ótima do conjugado, selecionadas para uso, foram determinadas previamente através de ensaios de titulação em placas de ELISA. Placas de poliestireno com orifícios de fundo chato (Corning, New York) fora recobertas com $200 \mu 1$ /orifício das preparações $E_{2}$ ou EU, diluídas a $4 \mu \mathrm{g}$ de proteína/ml com tampão carbonato-bicarbonato $0,1 \mathrm{M}, \mathrm{pH} 9,6$. Após incubação por $3 \mathrm{~h}$, a $37^{\circ} \mathrm{C}$, as placas foram lavadas três vezes com SST contendo $0,1 \%$ de Tween 20 (SST/Tw). A seguir, $200 \mu$ l das amostras dos soros diluídas em SST-Tw contendo $0,1 \%$ de albumina bovina sérica, foram adicionados aos orifícios. Após incubação por $1 \mathrm{~h}$, à temperatura ambiente, as placas foram lavadas com SST-Tw como previamente descrito. Duzentos microlitros do conjugado, imunoglobulina de cabra anti-IgG humana marcada com peroxidase, diluído a 1:750 com SST-Tw, foram adicionados aos orifícios e as placas foram deixadas em repouso por $1 \mathrm{~h}$, à temperatura ambiente. As placas foram lavadas com SST-Tw, como já descrito, e $200 \mu 1$ do sistema substrato foram adicionados aos orifícios. O sistema substrato era composto de 3,3', 5, $5^{\prime}$-tetrametilbenzidina e $\mathrm{H}_{2} \mathrm{O}_{2}$ nas concentrações finais de $0,42 \mathrm{mM}$ e $0,004 \%$, respectivamente. Trinta minutos após a adição do sistema substrato, as reações foram bloqueadas adicionando-se aos orifícios $50 \mu \mathrm{l} \mathrm{de} \mathrm{H}_{2} \mathrm{SO}_{4} 4 \mathrm{~N}$. As absorbâncias das reações foram lidas a $450 \mathrm{~nm}$ em uma leitora de placas. Todas as diluições dos soros foram testadas em triplicata e a densidade ótica (D.O.) média foi considerada. Todas as placas continham 8 replicatas do controle de antígeno. A $\tau\lrcorner$. final para cada diluição do soro foi determinada, subtraindo-se a média das D.O. dos 8 controles de antígenos. Um resultado foi considerado positivo, quando a D.O. final foi superior a 2 desvios-padrões (DP) acima da média de um grupo de soros negativos, obtidos de 12 indivíduos sem nenhuma evidência de estrongiloidíase, testados na mesma placa.

Soros

Os seguintes grupos de soros, provenientes de indivíduos infectados, foram utilizados: Strongyloides stercoralis $(\mathrm{n}=17)$; Ascaris lumbricoides $(\mathrm{n}=3)$; Schistosoma mansoni $(\mathrm{n}=3)$; Giardia lamblia $(\mathrm{n}=3)$; Hymenolepis nana $(\mathrm{n}=2)$; 
Rossi CL, Takahashi EEH, Teixeira ALS, Barros-Mazon S, Trevisan RCG. Avaliação de preparações antigênicas de Strongyloides stercoralis para o imunodiagnóstico da estrongiloidiase. Revista da Sociedade Brasileira de Medicina Tropical 26:83-87, abr-jun, 1993.

Enterobius vermicularis $(\mathrm{n}=2)$; Taenia $\mathrm{sp}(\mathrm{n}=2)$. O diagnóstico, em todos os grupos, foi determinado por meios parasitológicos. Em todos os casos, nenhuma infecção simultânea com outros parasitas intestinais foi observada, em pelo menos três exames de fezes consecutivos.

Um pool de soros reagentes para $S$. stercoralis foi obtido, misturando-se partes iguais de soros de indivíduos com estrongiloidíase, comprovada por meios parasitológicos e sorologia positiva para o parasita.

Os soros controles negativos foram obtidos de estudantes da Faculdade de Ciências Médicas da UNICAMP e de funcionários do nosso Departamento. Estes indivíduos tinham, pelo menos, três exames protoparasitológicos negativos e não tinham história passada de infecção por S. stercoralis.

\section{RESULTADOS}

Em termos de concentração de proteínas, a proporção entre as extrações com SST e uréia foi de $1,7: 1$.

As atividades antigênicas específicas das preparações ES e EU foram avaliadas, através de ELISA, utilizando os soros de indivíduos com estrongiloidíase diluídos a 1:10. Dos 17 soros testados, 13 foram reagentes com as duas preparações, 1 foi reagente com a preparação ES e duvidoso com a preparação EU e 3 não reagiram com as duas preparações. Um pool de 8 soros de indivíduos com estrongiloidíase e com sorologia positiva para $S$. stercoralis também foi testado por ELISA com as duas preparações. As densidades óticas finais das reações entre as preparações ES e EU e o pool de soros diluídos a $1 / 100$ foram, respectivamente, 0,75 e 0,74 .

A reatividade dos soros de indivíduos portadores de outras infecções parasitárias com as preparações ES e EU é mostrada na Tabela 1. Estes soros foram testados com diluições seriadas, começando em 1/10. Dos 15 soros testados, somente 2 reagiram com as duas preparações antigênicas. Estes eram provenientes de um indivíduo com esquistossomose e de um com ascaridíase. Nestes soros falsopositivos, não foram observadas diferenças significativas entre os títulos de ELISA obtidos com as preparações ES e EU.

Tabela 1 - Avaliação da reatividade entre preparações antigênicas de $\mathrm{S}$. stercoralis e soros de individuos portadores de infecções heterólogas, através de ELISA.

\begin{tabular}{cccc}
\hline$n^{\circ}$ caso & Tipo de infecção & \multicolumn{2}{c}{ Títulos de ELISA } \\
\cline { 3 - 4 } & & ES $^{\mathrm{B}}$ & $\mathrm{EU}^{\mathrm{C}}$ \\
\hline 1 & A. lumbricoides & 80 & 40 \\
2 & & $<10$ & $<10$ \\
3 & & $<10$ & $<10$ \\
4 & S. mansoni & 20 & 10 \\
5 & & $<10$ & $<10$ \\
6 & & $<10$ & $<10$ \\
7 & G. lamblia & $<10$ & $<10$ \\
8 & & $<10$ & $<10$ \\
9 & & $<10$ & $<10$ \\
10 & H. nana & $<10$ & $<10$ \\
11 & & $<10$ & $<10$ \\
12 & E. vermicularis & $<10$ & $<10$ \\
13 & & $<10$ & $<10$ \\
14 & Taenia sp & $<10$ & $<10$ \\
15 & & $<10$ & $<10$ \\
\hline
\end{tabular}

A Títulos foram expressos como as recíprocas das diluições dos soros.

B Preparação antigênica de $S$. stercoralis obtida com extração salina.

C Preparação antigênica obtida com solubilização pela uréia da fração residual de $S$. stercoralis resultante da extração salina. 
Rossi CL, Takahashi EEH, Teixeira ALS, Barros-Mazon S, Trevisan RCG. Avaliação de preparações antigênicas de Strongyloides stercoralis para o imunodiagnóstico da estrongiloidíase. Revista da Sociedade Brasileira de Medicina Tropical 26:83-87, abr-jun, 1993.

\section{DISCUSSÃO}

O diagnóstico definitivo de estrongiloidíase é dado, pelo achado de larvas de $S$. stercoralis nas fezes de pessoas infectadas. Entretanto, as larvas do parasita podem estar presentes em pequenas quantidades, ou mesmo ausentes dos materiais examinados, de modo que vários autores têm salientado a falta de sensibilidade dos métodos parasitológicos ${ }^{7} 10$. As técnicas sorológicas, principalmente as imunoenzimáticas, pc tem ser uma boa alternativa para o diagnó: tico da estrongiloidíase. A maioria dos trabalhos realizados, até o presente momento, indica que a sensibilidade das técnicas imunoenzimáticas para deteç̧ão de anticorpos específicos da classe IgG anti-S. stercoralis é próxima a $85 \% 1311$. A dificuldade de obtenção de larvas de $S$. stercoralis e, consequentemente, a obtenção de quantidades suficientes de material antigênico ativo, tem sido um fator limitante para o imunodiagnóstico da estrongiloidíase 5 .

Trabalhos prévios têm mostrado que antígenos ligados à membrana de parasitas podem ser solubilizados na presença de uréia ${ }^{1617}$. Os resultados do presente trabalho mostraram que a fração residual de S. stercoralis, resultante da extração salina, após solubilização com uréia, apresentou quantidades șignificativas de material antigênico ativo. As preparações antigênicas ES e EU parecem ter grau similar de reatividade cruzada com soros de indivíduos portadores de infecções heterólogas. Particularmente importante foi a forte reatividade observada com o soro de um indivíduo com ascaridíase. Essa reatividade cruzada também tem sido observada por outros autores, utilizando preparações antigênicas de $S$. stercoralis ou $S$. $\mathrm{ratti}^{4} 1015$.

A sensibilidade e a especificidade de uma técnica imunológica dependem, em grande parte, da preparação antigênica utilizada. A possibilidade de um maior rendimento de material antigênico de S. stercoralis, através de um segundo processo de extração, com uréia, abre perspectivas para o fracionamento do extrato bruto do parasita, na tentativa de se encontrar frações com maior atividade antigênica específica e menor reatividade cruzada.

\section{SUMMARY}

Aqueons-soluble (AS) antigens from larvae of Strongyloides stercoralis, extracted with phosphatebuffered saline, are traditionally used for serodiagnosis of strongyloidiasis. To identify sources of antigens for use in serodiagnosis, residual particulates from parasite larvae after aqueous extraction were solubilized with Tris-buffered $8 M$ urea, yielding a urea-soluble (US) antigen fraction. Both $A S$ and $U S$ antigens from $\mathbf{S}$. stercoralis were evaluated by an enzyme-linked immunosorbent assay. No significative differences were observed between $A S$ and US antigens from the parasite regarding specific antigenic activity and cross-reactivity. Immunoassays are highty dependent on the antigen for sensitivity and specificity. Crude extracts from $\mathrm{S}$. stercoralis should be further studied, mainly in relation to antigenic fractions which could provide even more sensitive and specific results. Studies of fractionation of S. stercoralis must take into account the antigen yield of both the crude extract and fractions, since larvae of parasite are normally difficult to obtain. Considering this aspect, the results from this study are very useful, since the extraction with urea substantially increased the amounts of antigenic materials normally obtained with the classical aqueous extraction.

Key-words: Strongyloides stercoralis. Strongyloidiasis. Inmunodiagnosis. Antigens.

\section{REFERÊNCIAS BIBLIOGRÁFICAS}

1. CarrollSM, Karthigasu KT, Grove DI. Serodiagnosis of human strongyloidiasis by an enzyme-linked immunosorbent assay. Transactions of the Royal Society of Tropical Medicine and Hygiene 75:706$709,1981$.

2. Carvalho-Filho E. Strongyloidiasis. Clinies in Gastroenterology 7:179-200, 1978.

3. Gam AA, Neva FA, Krotoski WA. Comparative sensitivity and specificity of ELISA and IHA for serodiagnosis of strongyloidiasis with larval antigens. American Journal of Tropical Medicine 37:157$161,1987$.

4. Genta RM. Predictive value of an enzyme-linked immunosorbent assay (ELISA) for the serodiagnosis of strongyloidiasis. American Journal of Clinical Pathology 89:391-394, 1988.

5. Genta RM. Global prevalence of strongyloidiasis: critical review with epidemiologic insights into the prevention of disseminated disease. Reviews of 
Rossi CL, Takahashi EEH, Teixeira ALS, Barros-Mazon S, Trevisan RCG. Avaliação de preparações antigênicas de Strongyloides stercoralis para o imunodiagnóstico da estrongiloidiase. Revista da Sociedade Brasileira de Medicina Tropical 26:83-87, abr-jun, 1993.

Infectious Diseases 11:755-767, 1989.

6. Genta RM, Weil GJ. Antibodies to Strongyloides stercoralis larval surface antigens in chronic strongyloidiasis. Laboratory Investigation 47:87$90,1982$.

7. Grove DI. Strongyloidiasis in Allied ex-prisoners of war in South-East Asia. British Medical Journal 280:598-601, 1980.

8. Grove DI, Blair J. Diagnosis of human strongyloidiasis by immunofluorescence, using Strongyloides ratti and S. stercoralis larvae. The American Journal of Tropical Medicineand Hygiene 30:344-349, 1981.

9. Milder JE, Walzer PD, Kilgore G, Rutherford I, Klein M. Clinical features of Strongy loides stercoralis infection in an endemic area of the United States. Gastroenterology 80:1481-1488, 1981.

10. Neva FA. Biology and immunology of human strongyloidiasis. Journal of Infectious Diseases 153:397-407, 1986.

11. Neva FA, Gam AA, Burke J. Comparison of larval antigens in an enzyme-linked immunosorbent assay for strongyloidiasis in humans. Journal of Infectious Diseases 144:427-432, 1981.

12. Rugai E, Mattos T, Brisola AP. Nova técnica para isolar larvas de nematóides das fezes; modificação do método de Baermann. Revista do Instituto Adolfo Lutz 14:5-8, 1954.

13. Sato $Y$, Ryumon I. Gelatin particle indirect agglutination test for serodiagnosis of human strongyloidiasis. Japanese Journal of Parasitology 39:213-219, 1990.

14. Sato Y, Takara M, Otsuru M. Detection of antibodies in strongyloidiasis by enzyme-linked immunosorbent assay (ELISA). Transactions of the Royal Society of Tropical Medicine and Hygiene 79:51-55, 1985.

15. Tribouley-Duret J, Tribouley J, Appriou M, Megraud RN. Application du test ELISA au diagnostic de la strongiloidose. Annales de Parasitologie 53:641-648, 1978.

16. Tsang VCW, Tao Y, Maddison SE. Systematic fractionation of Schistosoma mansoni urea-soluble egg antigens and their evaluation by the single-tube, kinetic-dependent, enzyme-linked, immunosorbent assay (k-ELISA). Journal of Parasitology 67:340$350,1981$.

17. Tsang VCW, Tsang KR, Hancock K, Kelly MA, Wilson BC, Maddison SE. Schistosoma mansoni adult microsomal antigens, a serologic reagent. I. Systematic fractionation, quantitation, and characterization of antigenic components. Journal of Immunology 130:1359-1365, 1981. 